\title{
Modulatory effects of photobiomodulation in the anterior cingulate cortex of diabetic rats
}

\author{
Igor Rafael Correia Rocha ${ }^{1} \cdot$ Marucia Chacur ${ }^{1}$ (i)
}

Received: 12 March 2021 / Accepted: 25 May 2021 / Published online: 30 May 2021

(c) The Author(s), under exclusive licence to European Photochemistry Association, European Society for Photobiology 2021

\begin{abstract}
Anterior Cingulate Cortex (ACC) has a crucial contribution to higher order pain processing. Photobiomodulation (PBM) has being used as integrative medicine for pain treatment and for a variety of nervous system disorders. This study evaluated the effects of PBM in the ACC of diabetic rats. Type 1 diabetes was induced by a single dose of streptozotocin $(85 \mathrm{mg} / \mathrm{Kg})$. A total of ten sessions of PBM (pulsed gallium-arsenide laser, $904 \mathrm{~nm}, 9500 \mathrm{~Hz}, 6.23 \mathrm{~J} / \mathrm{cm}^{2}$ ) was applied to the rat peripheral nervous system. Glial fibrillary acidic protein (GFAP), mu-opioid receptor (MOR), glutamate receptor 1 (GluR1), and glutamic acid decarboxylase (GAD65/67) protein level expression were analyzed in the ACC of diabetic rats treated with PBM. Our data revealed that PBM decreased 79.5\% of GFAP protein levels in the ACC of STZ rats. Moreover, STZ+ PBM rats had protein levels of MOR increased 14.7\% in the ACC. Interestingly, STZ+PBM rats had a decrease in 70.7\% of GluR1 protein level in the ACC. Additionally, PBM decreased 45.5\% of GAD65/67 protein levels in the ACC of STZ rats.
\end{abstract}

Keywords Diabetes $\cdot$ Hyperglycemia $\cdot$ Neuropathy $\cdot$ Phototherapy $\cdot$ Streptozotocin $\cdot$ Western blot

\section{Abbreviations \\ ACC Anterior cingulate cortex \\ i.p Intraperitoneal \\ PBM Photobiomodulation \\ STZ Streptozotocin}

\section{Introduction}

The anterior cingulate cortex (ACC) plays relevant role in pain perception [1], and despite its involvement in chronic pain development following peripheral nerve injury [2], however, the contribution of ACC to the experience of chronic pain in diabetic peripheral neuropathy (DPN) remains unclear. The ACC along with thalamus, insular cortex, prefrontal cortex, and somatosensory cortex is one of the main components of the pain matrix [3, 4]. Painrelated studies with animals have shown that ACC mediates

Marucia Chacur

chacurm@icb.usp.br

Igor Rafael Correia Rocha

ircrocha@usp.br

1 Departamento de Anatomia, Instituto de Ciências Biomédicas, Universidade de São Paulo, Avenue Lineu Prestes 2415, room 007, São Paulo 05508-900, Brazil responses to inflammatory pain, neuropathic pain, spontaneous pain in the formalin test, and formalin-induced conditioned place avoidance [5-8].

According to the International Diabetes Federation (IDF), there are approximately 463 million adults (20-79 years) living with diabetes worldwide, and by 2045, this will rise to 700 million (IDF ATLAS). This increase in the number of people with diabetes will be accompanied by an increase in the prevalence of diabetes complications [9]. Half of people living with diabetes develop DPN $[10,11]$, one of the leading causes of neuropathy worldwide [12]. DPN is characterized by the progressive loss of peripheral nerve fibers [13], and painful neuropathy is the main clinical consequences of this complex syndrome related to diabetes $[14,15]$. Additionally, there is no effective treatment that prevents peripheral nerve fiber degeneration in DPN [16], except tight glycaemic control [17].

Painful DPN is characterized by tingling, burning, sharp, shooting, and lancinating pain [18]. Pain can be constant and cutaneous allodynia may be present [19, 20], negatively affecting diabetic people mood [21, 22]. Furthermore, people living with painful DPN may also remove themselves from social activities and eventually develop depression [23, 24]. Given ACC involvement in the affective/motivational aspects of pain $[25,26]$ and its involvement in the glucose-monitoring network in the brain [27], it is of great 
importance to develop research that aims to investigate the ACC participation in processing pain in DPN, which is still unknown. Recalling what has already been mentioned, no single pharmacological treatment exists to prevent pain or provide total pain relieve in painful DPN [28].

Astrocyte activation or astrogliosis in ACC has been linked with chronic or neuropathic pain [29, 30]. Astrocytes are the most numerous non-neuronal cells in the brain involved in modulateng a variety of neuronal activities [31, 32], including glucose metabolism [33, 34]. Astrocytes were reported to highly express $\mu$-opioid receptor (MOR) [35], one of the three subtypes of opioid receptors that play important role in modulating pain behavior and antinociception [36]. Moreover, MOR are also efficacious mood enhancers and are involved in the activation of dopamine reward pathway [37, 38].

ACC is composed of both excitatory and inhibitory neurons [39, 40], and GABAergic transmission in the ACC plays a critical role in modulating nociception and chronic pain in humans and animal [41]. Glutamatergic AMPA ( $\alpha$ amino-3-hydroxy-5-methylisoxazole-4-propionic acid) receptors (GluR1, GluR2, GluR3, and GluR4) involved in a variety of central nervous system functions [42-44], including pain modulation [45], mediate the majority of excitatory synaptic transmission in the brain [46]. However, the roles of glutamatergic receptors in ACC during pain receive few attentions [6]. Additionally, changes in GABA content have recently been described in the central nervous system [47], including ACC of chronic pain patients [48, 49].

Based on the information presented here, the present study aimed to assess whether photobiomodulation (PBM) applied to the peripheral nervous system would have modulatory effects on the ACC in animal model of streptozotocin-induced DPN. PBM has been used as complementary medicine for chronic and neuropathic pain treatment [50, 51], nerve fibre regeneration [52], and a variety of diseases [53-57]. Of note, it is well known the beneficial effects of PBM on the central nervous system [58-61].

\section{Materials and methods}

\subsection{Animals}

The experiments were carried out in accordance with the CONCEA guidelines (CONCEA, Brazil), a constituent body of the Ministry of Science, Technology, and Innovation (MCTI, Brazil). All protocols, including STZ-induction type 1 diabetes and photobiomodulation therapy, were approved by the Animal Research Ethics Committee (CEUA) of the Biomedical Sciences Institute of the University Sao Paulo (protocol number: CEUA 2269190619). All animals were handled according to the guidelines for the use of laboratory animals [62]. The study used a total of 30 adult male Wistar rats (250-300 g) supplied by the central animal facility of the Biomedical Sciences Institute of University of Sao Paulo. Rats were kept at room temperature of $22 \pm 2{ }^{\circ} \mathrm{C}$ with light/dark cycle $(12: 12 \mathrm{~h})$. Food and water were provided ad libitum. The rats were allowed to acclimatize for at least 5 days prior to the onset of the study. They were randomly divided into three groups: (1) Naive rats were used as control animals (CTRL); (2) STZ animals, which were intraperitoneally injected with streptozotocin (STZ, $85 \mathrm{mg} / \mathrm{kg}$ ), and (3) STZ + PBM animals, which were injected with streptozotocin (STZ, $85 \mathrm{mg} / \mathrm{kg}$ ) and treated with photobiomodulation (PBM). After STZ i.p injection, three rats died along the experimental timeline. At the end of the study, we had nine rats per group.

\subsubsection{Streptozotocin-induced type 1 diabetes}

For the STZ-induced type 1 diabetes, a single dose of streptozotocin (85 mg/kg; S0130-1G, Sigma-Aldrich) diluted in $500 \mu \mathrm{L}$ of $0.9 \%$ Saline were injected in the peritoneal cavity [63]. Blood glucose levels were assessed $48 \mathrm{H}$ after STZ intraperitoneal injection to confirm hyperglycemia. Plasma glucose levels higher than $300 \mathrm{mg} / \mathrm{dl}$ were considered indicative of diabetes [64]. Glycemic control was assessed once a week using an ULTRAMINI ${ }^{\circledR}$ I ONETOUCH® blood glucose-monitoring system. A single administration of streptozotocin induced insulindependent diabetes mellitus within $48 \mathrm{H}$ by the destruction of pancreatic islet cells [65].

\subsection{Photobiomodulation}

Rats in the STZ + PBM group were irradiated with a GaAs laser (Gallium Arsenide, Laserpulse-Laser, Ibramed, Brazil) emitting a wavelength of $904 \mathrm{~nm}$, output power of $45 \mathrm{~mW}, 0.13 \mathrm{~cm}^{2}$ beam area, $9500 \mathrm{~Hz}$ frequency, duty cycle (DC) $0.0617 \%$, pulse time of $65 \mathrm{~ns}$, and $6.23 \mathrm{~J} / \mathrm{cm}^{2}$ fluence (Table 1). CTRL and STZ groups were not submitted to PBM. PBM initiated 60 days after diabetes induction. This time point was chosen, because we showed in a previous study that pain-related behavior (allodynia) and degeneration of peripheral nerve fibers were increased during persistent hyperglycaemia in the long term (60 days) [63]. The PBM treatment was performed under anesthesia with isoflurane (Cristalia, MG, Brazil) every other day totalling ten sessions. After sterilization, the laser probe was lightly placed on the unshaved skin surface of the rat's right thigh. Nine points in the region of the sciatic nerve were irradiated for $18 \mathrm{~s}$ each (Fig. 1). Points were irradiated between intervals of $30 \mathrm{~s}$. 
Table 1 Photobiomodulation parameters

\begin{tabular}{ll}
\hline Irradiation parameters & \\
Wavelength $(\mathrm{nm})$ & $904 \mathrm{~nm}$ \\
Operating mode & Pulsed \\
Frequency $(\mathrm{Hz})$ & $9500 \mathrm{~Hz}$ \\
Pulse on duration (nanoseconds) & $65 \mathrm{~ns}$ \\
Beam shape & Circular \\
Treatment parameters & \\
Beam spot size at target $\left(\mathrm{cm}^{2}\right)$ & $0.13 \mathrm{~cm}^{2}$ \\
Exposure duration $\left(\mathrm{seconds}^{2}\right)$ & $18 \mathrm{~s} / \mathrm{point}^{2}$ \\
Radiant exposure $\left(\mathrm{J} / \mathrm{cm}^{2}\right)$ & $6.23 \mathrm{~J} / \mathrm{cm}^{2}$ \\
Radiant energy $(\mathrm{J})$ & $0.81 /$ point \\
Number of points irradiated & 9 \\
Irradiated area $\left(\mathrm{cm}^{2}\right)$ & $1.17 \mathrm{~cm}{ }^{2}$ \\
Application technique & Skin contact \\
Number and frequency of treatment & 10 sessions \\
& performed \\
every \\
other day \\
Total radiant energy $(\mathrm{J})$ & $7.29 \mathrm{~J} /$ \\
& session. \\
& $72.9 \mathrm{~J}$ total \\
& sessions \\
\hline
\end{tabular}

\subsection{Protein expression analysis: Western blotting}

On the next day after the last PBM session (10th session), all the rats were anesthetized with 5\% isoflurane and decapitated when fully sedated. The animals' brains (anterior cingulate cortex) were removed for analysis of protein levels by Western blot assay. ACC were pooled from three rats of each group. Glial fibrillary acidic protein (GFAP), $\mu$-Opioid receptor (MOR), Glutamate Receptor 1
(GluR1), and Glutamic Acid Decarboxylase (GAD65/67) protein levels were quantified in the rat ACC. For total protein extraction, ACC was immersed in lysis buffer $(90 \mathrm{mM} \mathrm{KCl}, 10 \mathrm{mM}$ Hepes, $3 \mathrm{mM} \mathrm{MgCl} 2,5 \mathrm{mM}$ EDTA, $1 \%$ glycerol, $1 \mathrm{mM}$ DTT, 0.04\% SDS, $20 \mathrm{mM}$ Aprotinin, $20 \mathrm{mM}$ Pepstatin, $20 \mathrm{mM}$ Leupeptin, $40 \mu \mathrm{M}$ PMSF, $100 \mathrm{mM}$ Orthovanadate). The total protein concentration was obtained by Bradford method [66]. Subsequently, $40 \mu \mathrm{g}$ (ACC) of total protein underwent polyacrylamide gradient gel (4 and 20\%) [67] electrophoresis and transferred to nitrocellulose membrane (Bio-Rad). The membrane was subsequently stained with Ponceau solution to evaluate the similarity of protein concentration between the samples and for data normalization. Following Ponceau washing with TBST ( $20 \mathrm{mM}$ TRIS, $148 \mathrm{mM} \mathrm{NaCl}$, Tween $200.1 \%$ ), membrane was incubated with primary antibodies shown in Table 2 under constant agitation at $4{ }^{\circ} \mathrm{C}$ overnight. After washing with TBST, the membrane was incubated with the peroxidase-conjugated anti-rabbit (1:5000) secondary antibodies for MOR, GluR1, and GAD65/67 and with the anti-mouse (1:5000) secondary antibodies for GFAP and $\beta$-Actin, at room temperature for

Table 2 List of primary antibodies used for Western Blotting

\begin{tabular}{lllll}
\hline Antibody & Host species & $\begin{array}{l}\text { Molecular } \\
\text { weight }\end{array}$ & Dilution & RRID \\
\hline GFAP & Mouse & $50 \mathrm{KDa}$ & $1: 1000$ & AB_477010 \\
MOR & Rabbit & $50 \mathrm{KDa}$ & $1: 1000$ & AB_2156520 \\
GluR1 & Rabbit & $106 \mathrm{KDa}$ & $1: 1000$ & AB_2113602 \\
GAD65/67 & Rabbit & $65 / 67 \mathrm{KDa}$ & $1: 1000$ & AB_90715 \\
Beta-Actin & Mouse & $42 \mathrm{KDa}$ & $1: 5000$ & AB_476743 \\
\hline
\end{tabular}

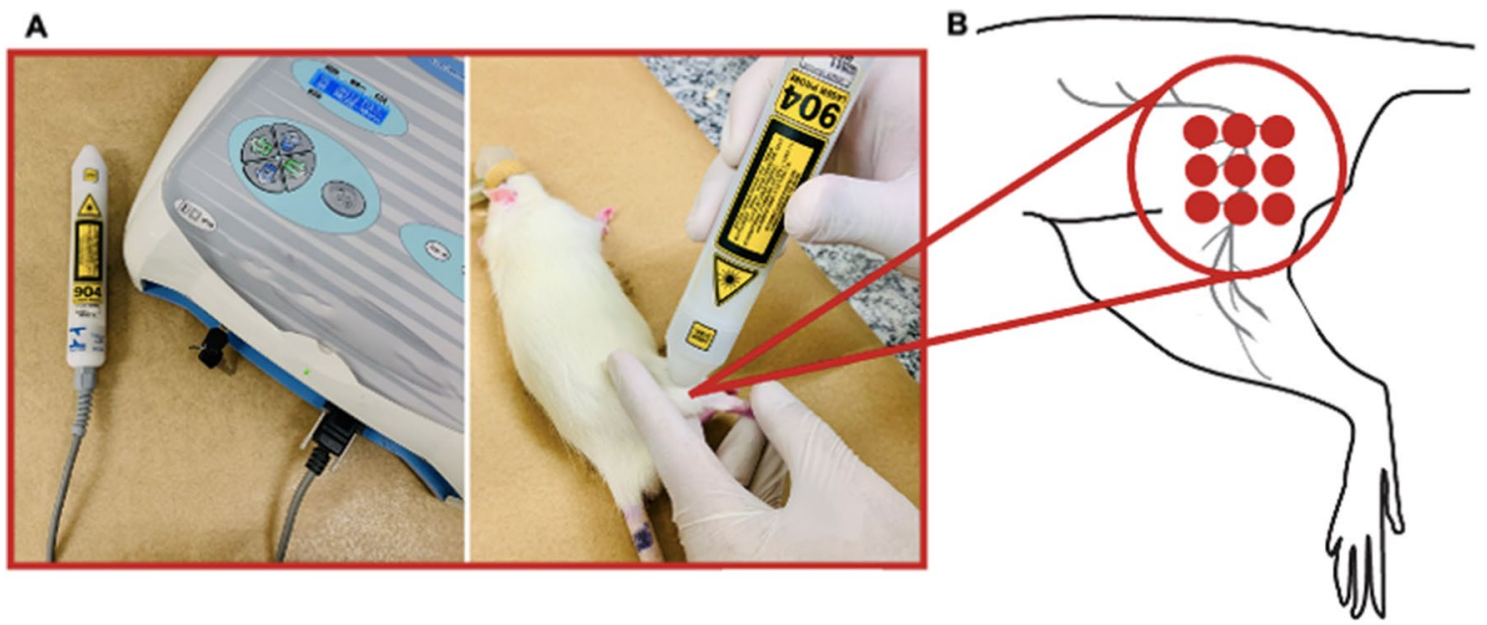

Fig. 1 Photobiomodulation session a Represents laser device and laser probe $(904 \mathrm{~nm})$. PBM sessions were applied to the rat peripheral nerve fibers by superficial skin contact—rats were anesthetized
$\left(\mathrm{O}_{2} /\right.$ Isoflurane) to receive PBM therapy. b Nine points were irradiated with PBM (904 nm) on the rat right leg 
$90 \mathrm{~min}$. The membrane was then washed again with TBST and submitted to chemiluminescence detector (UviTec Gel Doc Systems). The bands corresponding to the protein of interest were quantified by optical densitometry using the ImageJ software (NIH; USA), and the values were expressed as percentage [68]. For GFAP, MOR, GluR1, and GAD65/67, protein expression in the ACC, the same nitrocellulose membrane was used after stripping process for each antibody, and then, $\beta$-actin data were the same for all antibodies.

\section{Statistical analysis}

Statistical analyses of data were generated using GraphPAd Prism, version 8 (GraphPad Software Inc., San Diego, CA). For Western blot analysis statistical comparison among groups was performed using one-way analysis of variance; differences between means were tested by Bonferroni's multiple comparison test. In all cases, $p<0.05$ was considered statistically significant.

\section{Results}

\subsection{Type 1 diabetes onset through a single dose of STZ evaluated by blood glucose levels}

One single intraperitoneal injection of STZ $(85 \mathrm{mg} / \mathrm{kg})$ diluted in $500 \mu \mathrm{L}$ of Saline $0.9 \%$ was used to induce type 1 diabetes in male Wistar rats. The difference between means (STZ and CTRL) was $292.3 \mathrm{md} / \mathrm{dl}$ in ad libitum blood glucose level. STZ group had a mean blood glucose level of $387.7 \mathrm{mg} / \mathrm{dl}$ compared to CTRL, $95.40 \mathrm{mg} / \mathrm{dl}$. STZ revealed a significant blood glucose level increase compared to CTRL $[F(3,16)=313.6 ; p<0.0001]$ (Fig. 2)

\subsection{Effect of photobiomodulation on Glial Fibrillary Acidic Protein (GFAP) in the Anterior Cingulate Cortex (ACC)}

STZ group revealed an increase in GFAP protein expression in the ACC of diabetic rats, compared to CTRL and STZ + PBM groups (Fig. 3) $[F(2,6)=2859 ; p=0.0001]$. Western blotting data also revealed that PBM significantly decreased GFAP protein expression in the ACC in STZ + PBM group compared to STZ and CTRL groups $(p<0.0001)$. PBM decreased $138.52 \%$ of GFAP protein expression in the ACC of STZ + PBM group compared to STZ and $79.49 \%$ compared to CTRL (Fig. 3).

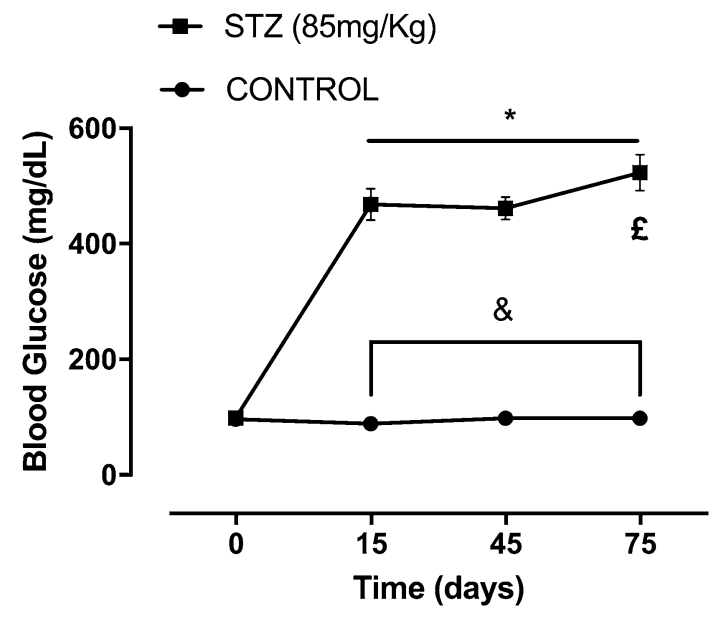

Fig. 2 Blood Glucose Effect of STZ on ad libitum blood glucose levels. $\& p<0.0001$ between Control and STZ. $* p<0.0001$ among 15 , 45,75 and day 0 in STZ. $£ p<0.0001$ among 75 and 45, 15 days in STZ
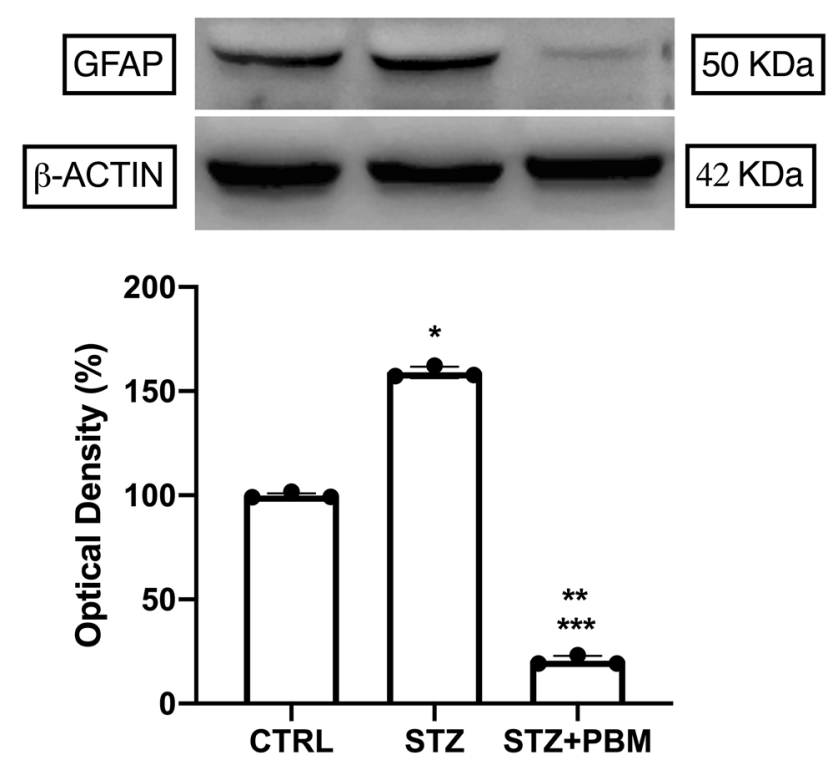

Fig. 3 Glial fibrillary acidic protein. Western blotting analysis of PBM on GFAP in the rat ACC. $* p<0.0001$ STZ/CTRL; $* * p<0.0001$ $\mathrm{STZ}+\mathrm{PBM} / \mathrm{STZ} ; * * * p<0.0001 \quad \mathrm{STZ}+\mathrm{PBM} / \mathrm{CTRL}$. Each black point in the graph represents a pool of three rats

\subsection{Effect of photobiomodulation on $\mu$-Opioid Receptor (MOR) in the Anterior Cingulate Cortex (ACC)}

STZ group revealed a decrease in MOR protein expression in the ACC of diabetic rats, compared to CTRL and STZ + PBM groups (Fig. 4) $[F(2,6)=39.05 ; p=0.0004]$. Western blotting data also revealed that PBM increased MOR protein expression in the ACC of STZ + PBM group compared to STZ $(p<0.0049)$ group. PBM increased $14.77 \%$ 


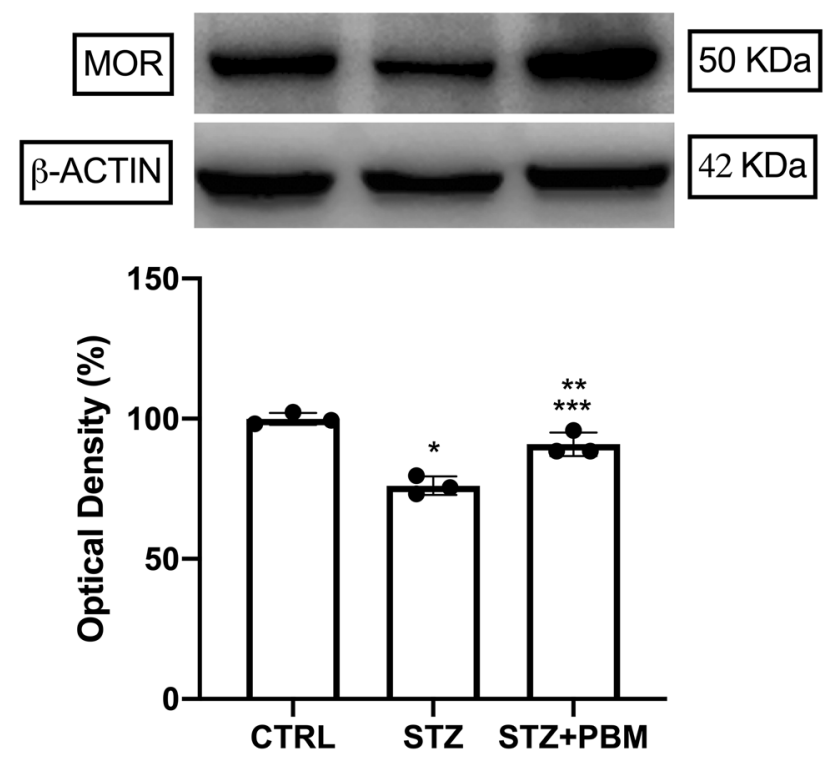

Fig. 4 Mu-opioid receptor. Western blotting analysis of PBM on MOR in the rat ACC. ${ }^{*} p<0.0004$ STZ/CTRL; $* * p<0.0049$ $\mathrm{STZ}+\mathrm{PBM} / \mathrm{STZ} ; * * * p<0.0467 \mathrm{STZ}+\mathrm{PBM} / \mathrm{CTRL}$. Each black point in the graph represents a pool of three rats

of MOR protein expression in the ACC of STZ+PBM group compared to STZ group (Fig. 4).

\subsection{Effect of photobiomodulation on Glutamate Receptor 1 (GluR1) in the Anterior Cingulate Cortex (ACC)}

STZ group revealed a decrease in GluR1 protein expression in the ACC of diabetic rats, compared to CTRL group (Fig. 5) $[F(2,6)=724.4 ; p=0.0001]$. Western blotting data also revealed an even greater decrease in STZ + PBM group compared to both groups. PBM decreased $10.48 \%$ of GluR1 protein expression in the ACC of STZ + PBM group compared to STZ and 70.7\% compared to CTRL (Fig. 5). STZ group had a decrease of $60.22 \%$ of GluR1 protein expression compared to CTRL.

\subsection{Effect of photobiomodulation on Glutamic Acid Decarboxylase (GAD65/67) in the Anterior Cingulate Cortex (ACC)}

STZ group revealed a decrease in GAD65/67 protein expression in the ACC compared to CTRL group (Fig. 6) $[F(2,6)=103.6 ; p=0.0001]$. After PBM treatment, our western blotting data revealed that $\mathrm{PBM}$ also decreased GAD65/67 protein expression in STZ + PBM group compared CTRL $(p<0.0001)$. STZ group had a decreased of $47.51 \%$ of GAD65/67 protein expression compared to CTRL and STZ + PBM had a decreased of $45.51 \%$ compared to CTRL (Fig. 6). No statistical difference was found

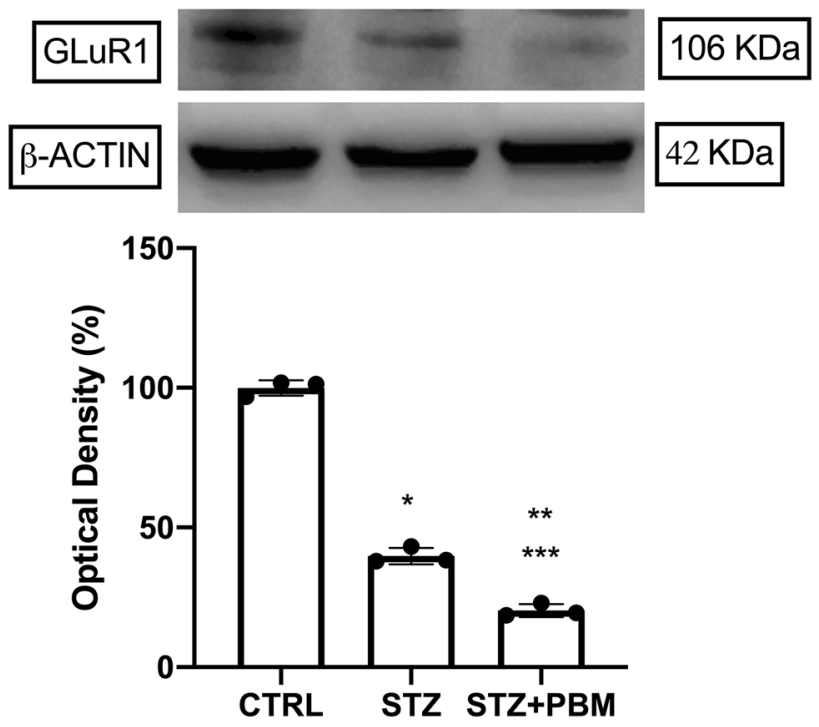

Fig. 5 Glutamate receptor 1 . Western blotting analysis of PBM on GluR1 in the rat ACC. $* p<0.0001$ STZ/CTRL; $* * p<0.0003$ $\mathrm{STZ}+\mathrm{PBM} / \mathrm{STZ} ; * * * p<0.0001 \mathrm{STZ}+\mathrm{PBM} / \mathrm{CTRL}$. Each black point in the graph represents a pool of three rats

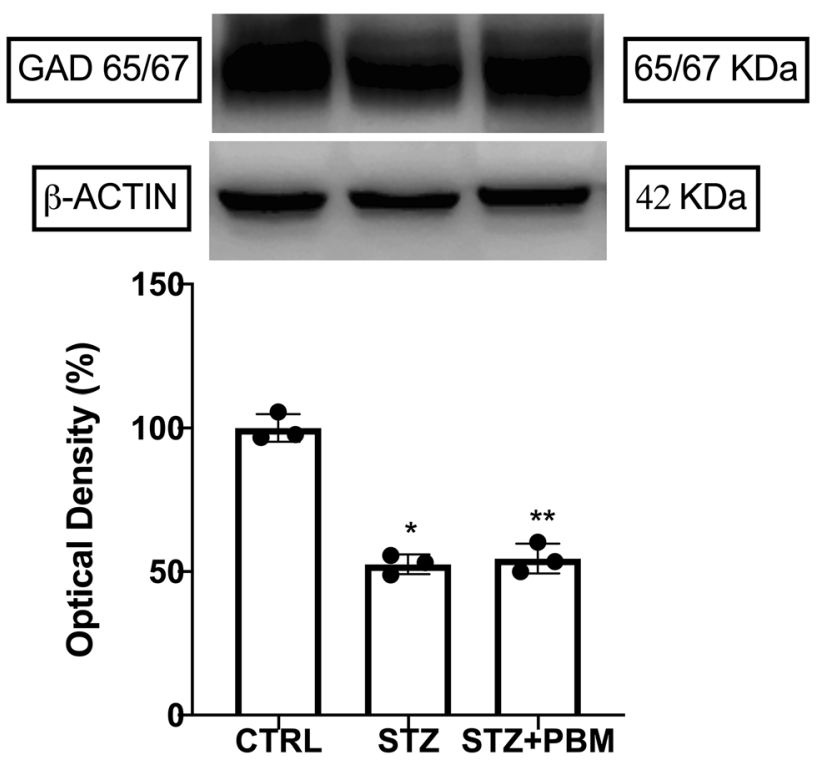

Fig. 6 Glutamic acid decarboxylase. Western blotting analysis of PBM on GAD65/67 in the rat ACC. ${ }^{*} p<0.0001$ STZ/CTRL; $* * p<0.0001$ STZ + PBM/CTRL. No statistical significance was found between STZ+PBM and STZ. Each black point in the graph represents a pool of three rats 
between STZ+ PBM and STZ regarding protein expression of GAD65/67 in the rat ACC.

\section{Discussion}

In the present study, we investigated the effects of PBM on the supraspinal brain region involved in the cognitive and emotional processing of peripheral painful sensation, ACC. In our study, we used rat model of diabetic peripheral neuropathy induced by a single dose of streptozotocin (STZ, $85 \mathrm{mg} / \mathrm{kg}$ ) injected in the peritoneal cavity (intraperitoneal, i.p). Rats that were injected with STZ developed hyperglycemia $24 \mathrm{~h}$ after STZ i.p injection. Furthermore, STZ-induced diabetic rats developed the most common signs of diabetic neuropathy. It includes severe weight loss, polyuria, polyphagia and, in some cases, cataracts (data not shown). Additionally, we have previously shown that one single dose of STZ $(85 \mathrm{mg} / \mathrm{kg})$ induced allodynia in rat model of diabetic peripheral neuropathy and that PBM restore pain threshold in those rats [63]. Streptozotocin-induced diabetic rats had an average blood glucose level of $387.7 \mathrm{mg} / \mathrm{dl}$. Control (CTRL) rats developed no signs of diabetic neuropathy and had an average blood glucose level of $95.40 \mathrm{mg} / \mathrm{dl}$ throughout the experimental timeline (12 weeks).

Currently, there is an increasing body of evidence showing the involvement of ACC in the perception of physical and affective components of pain [69-73]. Of note, little is known about the direct effects of hyperglycemia (diabetes) on ACC. Moreover, there is a limited but growing body of evidence concerning the effects of PBM on the brain [58, $60,61,74]$. Furthermore, less is known about how PBM that was applied to the peripheral nervous system has the potential to modulate protein levels in supraspinal segments in the central nervous system. We present here the modulatory effects of photobiomodulation on (1) glial fibrillary acidic protein (GFAP), (2) $\mu$-opioid receptor (MOR), and (3) glutamate receptor (GluR1) protein levels in the ACC of diabetic rats in streptozotocin-induced diabetic peripheral neuropathy.

Initially, our results showed that hyperglycemia increases GFAP protein levels in the ACC of diabetic rats (STZ) when compared to control (CTRL) group. It must be mentioned that one of the major roles played by astrocytes is their direct involvement in energy storage and supply for the brain [33, 75, 76]. Moreover, Coleman et al. [77] and Saraiva et al. [78] demonstrated changes in GFAP expression in the central nervous system (CNS) in rodent diabetes model. However, the effects of high glucose on astrocytes metabolism and function remains unclear [75]. Of note, we showed here that diabetic rats treated with PBM (STZ+ PBM) had a significant decrease of GFAP protein levels in the ACC when compared to STZ group. There was also statistical difference between STZ+ PBM and CTRL group.

It was also presented here that PBM increased $\mu$-opioid receptor (MOR) in the ACC of diabetic rats $(\mathrm{STZ}+\mathrm{PBM})$ when applied to the peripheral nervous system. STZ rats had a decrease in MOR protein levels when compared to CTRL group. Opioid receptors comprise four members, the classical $\mu$ (MOR), $\delta$ (DOR), and $\kappa$ (KOR) receptors, and the non-classical nociceptin/orphanin FQ (NOP) receptor [79]. MOR receptors are the most important class of receptors clinically, playing an important role in pain treatment $[36,80,81]$. Interestingly, MOR was reported to be highly expressed in the central nervous system astrocytes [82]. However, the role of astrocytic MOR has not been investigated [82, 83]. Furthermore, little is known about the role of astrocytes and MOR in diabetic peripheral neuropathy, especially regarding ACC.

In the present study, we also showed that hyperglycemia decreased glutamate receptor (GluR1) protein levels in the ACC of diabetic rats (STZ) compared to control (CTRL). Surprisingly, PBM decreased even further GluR1 protein levels in the diabetic rats (STZ) that were treated with PBM. Glutamate is the main excitatory neurotransmitter in the mammalian brain where astrocytes play an important role in removing $90 \%$ of such neurotransmitter from the synapse in the central nervous system [84, 85]. Bolo et al. [86] and Wiegers et al. [87] demonstrated elevated brain glutamate levels in people with type 1 diabetes, but they did not correlate such results with ionotropic glutamate receptor 1 (GluR1). Moreover, Andersen et al. [84] showed impaired glutamate and glutamine metabolism in the hippocampus of mouse model of type 2 diabetes but did not make any correlation between this finding and GluR1.

Additionally, we evaluated the effects of PBM on the modulation of protein levels of glutamic acid decarboxylase (GAD65/67) on the ACC of diabetic rats (STZ). GAD65/67 plays an important role in the synthesis of gamma-aminobutyric acid (GABA) in the central nervous system (CNS) [88]. GABA is the principal inhibitory transmitter in the CNS, including the spinal dorsal horn and ACC [88, 89]. Our results demonstrated that diabetic rats (STZ) had a significant decrease in the levels of GAD65/67 in the ACC compared to control rats. Interestingly, PBM had no effect in GAD65/67 protein levels of diabetic rats. The effects of hyperglycemia on GAD65/67 protein modulation should be further investigated.

Regarding the abscopal effects of PBM our data summarized here corroborates the findings presented by Mitrofranis et al. [90]. Mitrofanis and colleagues showed that ten consecutive days of remote PBM had neuroprotective effects in mice model of Parkinson's disease (PD) [90]. According to their study, remote PBM produces modest but widespread changes in the brain transcriptome [90]. With respect 
to working memory and cognitive functions in which ACC plays an important role, Salehpour et al. [91] demonstrated in a case report that an individual affected by Alzheimer's disease (AD) treated with transcranial e intranasal PBM had improvements in cognitive abilities, working memory, as well as in quality of life [91]. Another interesting finding with respect to indirect effects of PBM was demonstrated by Kern et al. [92]. In STZ-induced diabetes in mice, PBM attenuated diabetes-induced retinopathy by improving diabetic-changes in superoxide generation, leukostasis, and expression of ICAM-1 [92]. Kern and colleagues showed that such significant results were achieved with the mice's head protected from the light therapy, the retina itself did not receive PBM directly [92].

\section{Conclusion}

In conclusion, the present study demonstrated the abscopal effects of PBM on the ACC of diabetic rats. Interestingly, hyperglycemia had expressive modulatory effect on the protein levels of GFAP, MOR, GluR1, and GAD65/67 on the ACC of diabetic rats. Surprisingly, PBM applied to the peripheral nervous system of these diabetic animals modulated the protein levels of GFAP, MOR, and GluR1 on the ACC. PBM had no effect on the modulation of GAD65/67. Our results suggest that PBM applied to the periphery may have interesting effects on supraspinal brain regions, especially on the ACC. We must further investigate the effects of hyperglycemia in this brain region and why and how PBM that was applied to the peripheral nervous system elicits its effect on supraspinal brain region.

Acknowledgements This study was supported by Sao Paulo Research Foundation (FAPESP. Sao Paulo, Brazil). Igor Rafael Correia Rocha was the recipient of a FAPESP PhD scholarship (2017/25554-0). Marucia Chacur was the recipient of an FAPESP (2017/05218-5)/CNPq (405853/2018-1) fellowship. Igor Rafael Correia Rocha and Marucia Chacur have contributed equally to this work.

Funding This study was supported by Sao Paulo Research Foundation (FAPESP), grant number 2017/25554-0. The funding agency plays no role in the design of the study, data collection, analysis, interpretation of the data, or in writing the manuscript.

\section{Declarations}

Conflict of interest The authors declare no financial or commercial conflict of interest.

\section{References}

1. Zhuo, M. (2014). Long-term potentiation in the anterior cingulate cortex and chronic pain. Philosophical Transactions of the Royal
Society of London. Series B, Biological sciences, 369(1633), 20130146. https://doi.org/10.1098/rstb.2013.0146

2. Zhao, R., Zhou, H., Huang, L., Xie, Z., Wang, J., Gan, W. B., et al. (2018). Neuropathic pain causes pyramidal neuronal hyperactivity in the anterior cingulate cortex. Frontiers in Cellular Neuroscience, 12, 107. https://doi.org/10.3389/fncel.2018.00107

3. Um, S. W., Kim, M. J., Leem, J. W., Bai, S. J., \& Lee, B. H. (2019). Pain-relieving effects of mTOR inhibitor in the anterior cingulate cortex of neuropathic rats. Molecular Neurobiology, 56(4), 2482-2494. https://doi.org/10.1007/s12035-018-1245-z

4. Chai, S. C., Kung, J. C., \& Shyu, B. C. (2010). Roles of the anterior cingulate cortex and medial thalamus in short-term and long-term aversive information processing. Molecular Pain, 6, 42. https://doi.org/10.1186/1744-8069-6-42

5. Wu, L. J., Steenland, H. W., Kim, S. S., Isiegas, C., Abel, T., Kaang, B. K., et al. (2008). Enhancement of presynaptic glutamate release and persistent inflammatory pain by increasing neuronal cAMP in the anterior cingulate cortex. Molecular Pain, 4, 40. https://doi.org/10.1186/1744-8069-4-40

6. Xu, H., Wu, L. J., Wang, H., Zhang, X., Vadakkan, K. I., Kim, S. S., et al. (2008). Presynaptic and postsynaptic amplifications of neuropathic pain in the anterior cingulate cortex. Journal of Neuroscience, 28(29), 7445-7453. https://doi.org/10.1523/JNEUR OSCI.1812-08.2008

7. Fuchs, P. N., Balinsky, M., \& Melzack, R. (1996). Electrical stimulation of the cingulum bundle and surrounding cortical tissue reduces formalin-test pain in the rat. Brain Research, 743(1-2), 116-123. https://doi.org/10.1016/s0006-8993(96)01035-9

8. Johansen, J. P., Fields, H. L., \& Manning, B. H. (2001). The affective component of pain in rodents: direct evidence for a contribution of the anterior cingulate cortex. Proceedings of the National Academy of Sciences USA, 98(14), 8077-8082. https://doi.org/10. 1073/pnas.141218998

9. Iqbal, Z., Azmi, S., Yadav, R., Ferdousi, M., Kumar, M., Cuthbertson, D. J., et al. (2018). Diabetic peripheral neuropathy: epidemiology, diagnosis, and pharmacotherapy. Clinical Therapeutics, 40(6), 828-849. https://doi.org/10.1016/j.clinthera.2018.04.001

10. Albers, J. W., \& Pop-Busui, R. (2014). Diabetic neuropathy: mechanisms, emerging treatments, and subtypes. Current Neurology and Neuroscience Reports, 14(8), 473. https://doi.org/10. 1007/s11910-014-0473-5

11. Young, M. J., Boulton, A. J., MacLeod, A. F., Williams, D. R., \& Sonksen, P. H. (1993). A multicentre study of the prevalence of diabetic peripheral neuropathy in the United Kingdom hospital clinic population. Diabetologia, 36(2), 150-154. https://doi.org/ 10.1007/BF00400697

12. Schreiber, A. K., Nones, C. F., Reis, R. C., Chichorro, J. G., \& Cunha, J. M. (2015). Diabetic neuropathic pain: physiopathology and treatment. World Journal of Diabetes, 6(3), 432-444. https:// doi.org/10.4239/wjd.v6.i3.432

13. Tesfaye, S., Boulton, A. J., \& Dickenson, A. H. (2013). Mechanisms and management of diabetic painful distal symmetrical polyneuropathy. Diabetes Care, 36(9), 2456-2465. https://doi. org/10.2337/dc12-1964

14. Boulton, A. J., Kirsner, R. S., \& Vileikyte, L. (2004). Clinical practice. Neuropathic diabetic foot ulcers. New England Journal of Medicine, 351(1), 48-55. https://doi.org/10.1056/NEJMcp0329 66

15. Kaur, S., Pandhi, P., \& Dutta, P. (2011). Painful diabetic neuropathy: an update. Annals of Neurosciences, 18(4), 168-175. https:// doi.org/10.5214/ans.0972-7531.1118409

16. Boucek, P. (2006). Advanced diabetic neuropathy: a point of no return? The Review of Diabetic Studies, 3(3), 143-150. https://doi. org/10.1900/RDS.2006.3.143

17. Ang, L., Jaiswal, M., Martin, C., \& Pop-Busui, R. (2014). Glucose control and diabetic neuropathy: lessons from recent large 
clinical trials. Current Diabetes Reports, 14(9), 528. https://doi. org/10.1007/s11892-014-0528-7

18. Bansal, V., Kalita, J., \& Misra, U. K. (2006). Diabetic neuropathy. Postgraduate Medical Journal, 82(964), 95-100. https:// doi.org/10.1136/pgmj.2005.036137

19. Marchettini, P., Lacerenza, M., Mauri, E., \& Marangoni, C. (2006). Painful peripheral neuropathies. Current Neuropharmacology, 4(3), 175-181. https://doi.org/10.2174/1570159067 78019536

20. Aslam, A., Singh, J., \& Rajbhandari, S. (2014). Pathogenesis of painful diabetic neuropathy. Pain Research and Treatment, 2014, 412041. https://doi.org/10.1155/2014/412041

21. Girach, A., Julian, T. H., Varrassi, G., Paladini, A., Vadalouka, A., \& Zis, P. (2019). Quality of life in painful peripheral neuropathies: a systematic review. Pain Research \& Management, 2019, 2091960. https://doi.org/10.1155/2019/2091960

22. Selvarajah, D., Cash, T., Sankar, A., Thomas, L., Davies, J., Cachia, E., et al. (2014). The contributors of emotional distress in painful diabetic neuropathy. Diabetes \& Vascular Disease Research, 11(4), 218-225. https://doi.org/10.1177/1479164114 522135

23. Jain, R., Jain, S., Raison, C. L., \& Maletic, V. (2011). Painful diabetic neuropathy is more than pain alone: examining the role of anxiety and depression as mediators and complicators. Current Diabetes Reports, 11(4), 275-284. https://doi.org/10.1007/ s11892-011-0202-2

24. Vileikyte, L., Peyrot, M., Gonzalez, J. S., Rubin, R. R., Garrow, A. P., Stickings, D., et al. (2009). Predictors of depressive symptoms in persons with diabetic peripheral neuropathy: a longitudinal study. Diabetologia, 52(7), 1265-1273. https://doi. org/10.1007/s00125-009-1363-2

25. Fuchs, P. N., Peng, Y. B., Boyette-Davis, J. A., \& Uhelski, M. L. (2014). The anterior cingulate cortex and pain processing. Frontiers in Integrative Neuroscience, 8, 35. https://doi.org/10. 3389/fnint.2014.00035

26. Huang, J., Zhang, Z., \& Zamponi, G. W. (2020). Pain: integration of sensory and affective aspects of pain. Current Biology, 30(9), R393-R395. https://doi.org/10.1016/j.cub.2020.02.056

27. Hormay, E., Laszlo, B., Szabo, I., Ollmann, T., Nagy, B., Peczely, L., et al. (2019). The effect of loss of the glucose-monitoring neurons in the anterior cingulate cortex: physiologic challenges induce complex feeding-metabolic alterations after local streptozotocin microinjection in rats. Neuroscience Research, 149, 50-60. https://doi.org/10.1016/j.neures.2019.01.005

28. Javed, S., Petropoulos, I. N., Alam, U., \& Malik, R. A. (2015). Treatment of painful diabetic neuropathy. Therapeutic Advances in Chronic Disease, 6(1), 15-28. https://doi.org/10.1177/20406 22314552071

29. Masocha, W. (2015). Astrocyte activation in the anterior cingulate cortex and altered glutamatergic gene expression during paclitaxel-induced neuropathic pain in mice. PeerJ, 3, e1350. https://doi.org/10.7717/peerj.1350

30. Kuzumaki, N., Narita, M., Narita, M., Hareyama, N., Niikura, K., Nagumo, Y., et al. (2007). Chronic pain-induced astrocyte activation in the cingulate cortex with no change in neural or glial differentiation from neural stem cells in mice. Neuroscience Letters, 415(1), 22-27. https://doi.org/10.1016/j.neulet. 2006.12.057

31. Maragakis, N. J., \& Rothstein, J. D. (2006). Mechanisms of disease: astrocytes in neurodegenerative disease. Nature Clinical Practice Neurology, 2(12), 679-689. https://doi.org/10.1038/ ncpneuro0355

32. Seifert, G., Schilling, K., \& Steinhauser, C. (2006). Astrocyte dysfunction in neurological disorders: a molecular perspective. Nature Reviews Neuroscience, 7(3), 194-206. https://doi.org/10. 1038/nrn1870
33. Deitmer, J. W., Theparambil, S. M., Ruminot, I., Noor, S. I., \& Becker, H. M. (2019). Energy dynamics in the brain: contributions of astrocytes to metabolism and $\mathrm{pH}$ homeostasis. Frontiers in Neuroscience, 13, 1301. https://doi.org/10.3389/fnins.2019. 01301

34. Belanger, M., Allaman, I., \& Magistretti, P. J. (2011). Brain energy metabolism: focus on astrocyte-neuron metabolic cooperation. Cell Metabolism, 14(6), 724-738. https://doi.org/10.1016/j. cmet.2011.08.016

35. Woo, D. H., Bae, J. Y., Nam, M.-H., An, H., Ju, Y. H., Won, J., et al. (2018). Activation of astrocytic $\mu$-opioid receptor elicits fast glutamate release through TREK-1-containing K2P channel in hippocampal astrocytes. Frontiers in Cellular Neuroscience. https://doi.org/10.3389/fncel.2018.00319 Original Research.

36. Al-Hasani, R., \& Bruchas, M. R. (2011). Molecular mechanisms of opioid receptor-dependent signaling and behavior. Anesthesiology, 115(6), 1363-1381. https://doi.org/10.1097/ALN.0b013 e318238bba6

37. Lutz, P. E., \& Kieffer, B. L. (2013). Opioid receptors: distinct roles in mood disorders. Trends in Neurosciences, 36(3), 195-206. https://doi.org/10.1016/j.tins.2012.11.002

38. Le Merrer, J., Becker, J. A., Befort, K., \& Kieffer, B. L. (2009). Reward processing by the opioid system in the brain. Physiological Reviews, 89(4), 1379-1412. https://doi.org/10.1152/physrev. 00005.2009

39. Kang, S. J., Kim, S., Lee, J., Kwak, C., Lee, K., Zhuo, M., et al. (2017). Inhibition of anterior cingulate cortex excitatory neuronal activity induces conditioned place preference in a mouse model of chronic inflammatory pain. The Korean Journal of Physiology \& Pharmacology, 21(5), 487-493. https://doi.org/10.4196/kjpp. 2017.21.5.487

40. Yang, Z., Tan, Q., Cheng, D., Zhang, L., Zhang, J., Gu, E. W., et al. (2018). The changes of intrinsic excitability of pyramidal neurons in anterior cingulate cortex in neuropathic pain. Frontiers in Cellular Neuroscience, 12, 436. https://doi.org/10.3389/fncel. 2018.00436

41. Koga, K., Shimoyama, S., Yamada, A., Furukawa, T., Nikaido, Y., Furue, H., et al. (2018). Chronic inflammatory pain induced GABAergic synaptic plasticity in the adult mouse anterior cingulate cortex. Molecular Pain, 14, 1744806918783478. https://doi. org/10.1177/1744806918783478

42. Ceprian, M., \& Fulton, D. (2019). Glial cell AMPA receptors in nervous system health, injury and disease. International Journal of Molecular Sciences. https://doi.org/10.3390/ijms20102450

43. Chater, T. E., \& Goda, Y. (2014). The role of AMPA receptors in postsynaptic mechanisms of synaptic plasticity. Frontiers in Cellular Neuroscience, 8, 401. https://doi.org/10.3389/fncel.2014. 00401

44. Jones, E. V., Bernardinelli, Y., Zarruk, J. G., Chierzi, S., \& Murai, K. K. (2018). SPARC and GluA1-containing AMPA receptors promote neuronal health following CNS injury. Frontiers in Cellular Neuroscience, 12, 22. https://doi.org/10.3389/fncel.2018. 00022

45. Bie, B., Brown, D. L., \& Naguib, M. (2011). Increased synaptic GluR1 subunits in the anterior cingulate cortex of rats with peripheral inflammation. European Journal of Pharmacology, 653(1-3), 26-31. https://doi.org/10.1016/j.ejphar.2010.11.027

46. Zhang, H., \& Bramham, C. R. (2020). Bidirectional dysregulation of AMPA receptor-mediated synaptic transmission and plasticity in brain disorders. Frontiers in Synaptic Neuroscience, 12, 26. https://doi.org/10.3389/fnsyn.2020.00026

47. Blom, S. M., Pfister, J. P., Santello, M., Senn, W., \& Nevian, T. (2014). Nerve injury-induced neuropathic pain causes disinhibition of the anterior cingulate cortex. Journal of Neuroscience, 34(17), 5754-5764. https://doi.org/10.1523/JNEUROSCI.366713.2014 
48. Henderson, L. A., Peck, C. C., Petersen, E. T., Rae, C. D., Youssef, A. M., Reeves, J. M., et al. (2013). Chronic pain: lost inhibition? Journal of Neuroscience, 33(17), 7574-7582. https://doi.org/10.1523/JNEUROSCI.0174-13.2013

49. Foerster, B. R., Petrou, M., Edden, R. A., Sundgren, P. C., Schmidt-Wilcke, T., Lowe, S. E., et al. (2012). Reduced insular gamma-aminobutyric acid in fibromyalgia. Arthritis and Rheumatism, 64(2), 579-583. https://doi.org/10.1002/art.33339

50. Kingsley, J. D., Demchak, T., \& Mathis, R. (2014). Low-level laser therapy as a treatment for chronic pain. Frontiers in Physiology, 5, 306. https://doi.org/10.3389/fphys.2014.00306

51. de Andrade, A. L., Bossini, P. S., \& Parizotto, N. A. (2016). Use of low level laser therapy to control neuropathic pain: a systematic review. Journal of Photochemistry and Photobiology B: Biology, 164, 36-42. https://doi.org/10.1016/j.jphotobiol.2016. 08.025

52. Wang, C. Z., Chen, Y. J., Wang, Y. H., Yeh, M. L., Huang, M. H., Ho, M. L., et al. (2014). Low-level laser irradiation improves functional recovery and nerve regeneration in sciatic nerve crush rat injury model. PLoS ONE, 9(8), e103348. https://doi. org/10.1371/journal.pone.0103348

53. Posten, W., Wrone, D. A., Dover, J. S., Arndt, K. A., Silapunt, S., \& Alam, M. (2005). Low-level laser therapy for wound healing: mechanism and efficacy. Dermatologic Surgery, 31(3), 334-340. https://doi.org/10.1111/j.1524-4725.2005.31086

54. Lee, J. H., Chiang, M. H., Chen, P. H., Ho, M. L., Lee, H. E., \& Wang, Y. H. (2018). Anti-inflammatory effects of low-level laser therapy on human periodontal ligament cells: in vitro study. Lasers in Medical Science, 33(3), 469-477. https://doi. org/10.1007/s10103-017-2376-6

55. Angelova, A., \& Ilieva, E. M. (2016). Effectiveness of high intensity laser therapy for reduction of pain in knee osteoarthritis. Pain Research \& Management, 2016, 9163618. https://doi. org/10.1155/2016/9163618

56. Cotler, H. B., Chow, R. T., Hamblin, M. R., \& Carroll, J. (2015). The Use of Low Level Laser Therapy (LLLT) For Musculoskeletal Pain. MOJ Orthopedics \& Rheumatology. https://doi.org/ 10.15406/mojor.2015.02.00068

57. Sun, G., \& Tuner, J. (2004). Low-level laser therapy in dentistry. Dental Clinics of North America, 48(4), 1061-1076. https://doi. org/10.1016/j.cden.2004.05.004

58. Hashmi, J. T., Huang, Y. Y., Osmani, B. Z., Sharma, S. K., Naeser, M. A., \& Hamblin, M. R. (2010). Role of low-level laser therapy in neurorehabilitation. $P M \& R$ : The Journal of Injury, Function, and Rehabilitation, 2(12 Suppl 2), S292-305. https:// doi.org/10.1016/j.pmrj.2010.10.013

59. Rochkind, S., \& Ouaknine, G. E. (1992). New trend in neuroscience: low-power laser effect on peripheral and central nervous system (basic science, preclinical and clinical studies). Neurological Research, 14(1), 2-11. https://doi.org/10.1080/01616 412.1992.11740003

60. Thunshelle, C., \& Hamblin, M. R. (2016). Transcranial lowlevel laser (light) therapy for brain injury. Photomedicine and Laser Surgery, 34(12), 587-598. https://doi.org/10.1089/pho. 2015.4051

61. Hamblin, M. R. (2016). Shining light on the head: photobiomodulation for brain disorders. BBA Clinical, 6, 113-124. https://doi. org/10.1016/j.bbacli.2016.09.002

62. Zimmermann, M. (1983). Ethical guidelines for investigations of experimental pain in conscious animals. Pain, 16(2), 109-110. https://doi.org/10.1016/0304-3959(83)90201-4

63. Correia Rocha, I. R., Ciena, A. P., Rosa, A. S., Martins, D. O., \& Chacur, M. (2017). Photobiostimulation reverses allodynia and peripheral nerve damage in streptozotocin-induced type 1 diabetes. Lasers in Medical Science, 32(3), 495-501. https://doi.org/ 10.1007/s10103-016-2140-3
64. Pandurangan, M., \& Kim, D. H. (2016). Therapeutic potential of cyanobacteria against streptozotocin-induced diabetic rats. 3 Biotech, 6(1), 94. https://doi.org/10.1007/s13205-016-0411-0

65. Lenzen, S. (2008). The mechanisms of alloxan- and streptozotocin-induced diabetes. Diabetologia, 51(2), 216-226. https:// doi.org/10.1007/s00125-007-0886-7

66. Bradford, M. M. (1976). A rapid and sensitive method for the quantitation of microgram quantities of protein utilizing the principle of protein-dye binding. Analytical Biochemistry, 72, 248-254. https://doi.org/10.1006/abio.1976.9999

67. Miller, A. J., Roman, B., \& Norstrom, E. M. (2016). Protein electrophoretic migration data from custom and commercial gradient gels. Data in Brief, 9, 1-3. https://doi.org/10.1016/j. dib.2016.08.018

68. Binda, K. H., Real, C. C., Ferreira, A. F. F., Britto, L. R., \& Chacur, M. (2020). Antinociceptive effects of treadmill exercise in a rat model of Parkinson's disease: the role of cannabinoid and opioid receptors. Brain Research, 1727, 146521. https://doi. org/10.1016/j.brainres.2019.146521

69. Li, W., Wang, P., \& Li, H. (2014). Upregulation of glutamatergic transmission in anterior cingulate cortex in the diabetic rats with neuropathic pain. Neuroscience Letters, 568, 29-34. https://doi. org/10.1016/j.neulet.2014.03.038

70. Han, M., Xiao, X., Yang, Y., Huang, R. Y., Cao, H., Zhao, Z. Q., et al. (2014). SIP30 is required for neuropathic pain-evoked aversion in rats. Journal of Neuroscience, 34(2), 346-355. https://doi.org/10.1523/JNEUROSCI.3160-13.2014

71. Li, X. Y., Ko, H. G., Chen, T., Descalzi, G., Koga, K., Wang, H., et al. (2010). Alleviating neuropathic pain hypersensitivity by inhibiting PKMzeta in the anterior cingulate cortex. Science, 330(6009), 1400-1404. https://doi.org/10.1126/science.11917 92

72. Zhuo, M. (2008). Cortical excitation and chronic pain. Trends in Neurosciences, 31(4), 199-207. https://doi.org/10.1016/j.tins. 2008.01.003

73. Zhuo, M. (2006). Molecular mechanisms of pain in the anterior cingulate cortex. Journal of Neuroscience Research, 84(5), 927933. https://doi.org/10.1002/jnr.21003

74. Xuan, W., Vatansever, F., Huang, L., Wu, Q., Xuan, Y., Dai, T., et al. (2013). Transcranial low-level laser therapy improves neurological performance in traumatic brain injury in mice: effect of treatment repetition regimen. PLoS ONE, 8(1), e53454. https:// doi.org/10.1371/journal.pone.0053454

75. Li, W., Roy Choudhury, G., Winters, A., Prah, J., Lin, W., Liu, R., et al. (2018). Hyperglycemia alters astrocyte metabolism and inhibits astrocyte proliferation. Aging and Disease, 9(4), 674-684. https://doi.org/10.14336/AD.2017.1208

76. Prebil, M., Jensen, J., Zorec, R., \& Kreft, M. (2011). Astrocytes and energy metabolism. Archives of Physiology and Biochemistry, 117(2), 64-69. https://doi.org/10.3109/13813455.2010.539616

77. Coleman, E., Judd, R., Hoe, L., Dennis, J., \& Posner, P. (2004). Effects of diabetes mellitus on astrocyte GFAP and glutamate transporters in the CNS. Glia, 48(2), 166-178. https://doi.org/10. 1002/glia.20068

78. Saravia, F. E., Revsin, Y., Gonzalez Deniselle, M. C., Gonzalez, S. L., Roig, P., Lima, A., et al. (2002). Increased astrocyte reactivity in the hippocampus of murine models of type 1 diabetes: the nonobese diabetic (NOD) and streptozotocin-treated mice. Brain Research, 957(2), 345-353. https://doi.org/10.1016/s00068993(02)03675-2

79. Machelska, H., \& Celik, M. O. (2020). Opioid receptors in immune and glial cells-implications for pain control. Frontiers in Immunology, 11, 300. https://doi.org/10.3389/fimmu.2020.00300

80. Pasternak, G., \& Pan, Y. X. (2011). Mu opioid receptors in pain management. Acta Anaesthesiologica Taiwanica, 49(1), 21-25. https://doi.org/10.1016/j.aat.2010.12.008 
81. Ehrlich, A. T., Kieffer, B. L., \& Darcq, E. (2019). Current strategies toward safer mu opioid receptor drugs for pain management. Expert Opinion on Therapeutic Targets, 23(4), 315-326. https:// doi.org/10.1080/14728222.2019.1586882

82. Woo, D. H., Bae, J. Y., Nam, M. H., An, H., Ju, Y. H., Won, J., et al. (2018). Activation of astrocytic mu-opioid receptor elicits fast glutamate release through TREK-1-containing K2P channel in hippocampal astrocytes. Frontiers in Cellular Neuroscience, 12, 319. https://doi.org/10.3389/fncel.2018.00319

83. Nam, M. H., Han, K. S., Lee, J., Won, W., Koh, W., Bae, J. Y., et al. (2019). Activation of astrocytic mu-opioid receptor causes conditioned place preference. Cell Reports, 28(5), 1154-1166.e5. https://doi.org/10.1016/j.celrep.2019.06.071

84. Andersen, J. V., Nissen, J. D., Christensen, S. K., Markussen, K. H., \& Waagepetersen, H. S. (2017). Impaired hippocampal glutamate and glutamine metabolism in the $\mathrm{db} / \mathrm{db}$ mouse model of type 2 diabetes mellitus. Neural Plasticity, 2017, 2107084. https://doi. org/10.1155/2017/2107084

85. Mahmoud, S., Gharagozloo, M., Simard, C., \& Gris, D. (2019). Astrocytes maintain glutamate homeostasis in the CNS by controlling the balance between glutamate uptake and release. Cells. https://doi.org/10.3390/cells8020184

86. Bolo, N. R., Jacobson, A. M., Musen, G., Keshavan, M. S., \& Simonson, D. C. (2020). Acute hyperglycemia increases brain pregenual anterior cingulate cortex glutamate concentrations in type 1 diabetes. Diabetes, 69(7), 1528-1539. https://doi.org/10. 2337/db19-0936

87. Wiegers, E. C., Rooijackers, H. M., van Asten, J. J. A., Tack, C. J., Heerschap, A., de Galan, B. E., et al. (2019). Elevated brain glutamate levels in type 1 diabetes: correlations with glycaemic control and age of disease onset but not with hypoglycaemia awareness status. Diabetologia, 62(6), 1065-1073. https://doi. org/10.1007/s00125-019-4862-9

88. Kami, K., Taguchi Ms, S., Tajima, F., \& Senba, E. (2016). Improvements in impaired GABA and GAD65/67 production in the spinal dorsal horn contribute to exercise-induced hypoalgesia in a mouse model of neuropathic pain. Molecular Pain. https:// doi.org/10.1177/1744806916629059

89. Levar, N., van Leeuwen, J. M. C., Puts, N. A. J., Denys, D., \& van Wingen, G. A. (2017). GABA concentrations in the anterior cingulate cortex are associated with fear network function and fear recovery in humans. Frontiers in Human Neuroscience, 11, 202. https://doi.org/10.3389/fnhum.2017.00202

90. Ganeshan, V., Skladnev, N. V., Kim, J. Y., Mitrofanis, J., Stone, J., \& Johnstone, D. M. (2019). Pre-conditioning with remote photobiomodulation modulates the brain transcriptome and protects against MPTP insult in mice. Neuroscience, 400, 85-97. https:// doi.org/10.1016/j.neuroscience.2018.12.050

91. Salehpour, F., Hamblin, M. R., \& DiDuro, J. O. (2019). Rapid reversal of cognitive decline, olfactory dysfunction, and quality of life using multi-modality photobiomodulation therapy: case report. Photobiomodulation, Photomedicine, and Laser Surgery, 37(3), 159-167. https://doi.org/10.1089/photob.2018.4569

92. Saliba, A., Du, Y., Liu, H., Patel, S., Roberts, R., Berkowitz, B. A., et al. (2015). Photobiomodulation mitigates diabetes-induced retinopathy by direct and indirect mechanisms: evidence from intervention studies in pigmented mice. PLOS ONE, 10(10), e0139003. https://doi.org/10.1371/journal.pone.0139003 